\title{
MELHORAMENTO DO CAJUEIRO-ANÃO-PRECOCE: AVALIAÇÃO DA QUALIDADE DO PEDÚNCULO E A HETEROSE DOS SEUS HÍBRIDOS ${ }^{1}$
}

\author{
JOÃO RIBEIRO CRISÓSTOMO², JOSÉ JAIME VASCONCELOS CAVALCANTI ${ }^{3}$, LEVI DE MOURA \\ BARROS $^{2}$, RICARDO ELESBÃO ALVES ${ }^{2}$, JALMI GUEDES FREITAS ${ }^{4}$, JANSER NOBRE OLIVEIRA ${ }^{4}$
}

\begin{abstract}
RESUMO - O consumo de pedúnculo de caju “in natura” vem experimentando incremento no Brasil após o cultivo dos novos clones de cajueiro-anão-precoce lançados nos anos oitenta. Apesar desses avanços, o consumo ainda é reduzido, uma vez que não ultrapassa $1 \%$ das cerca de 1,5 milhão de toneladas anuais produzidas no Nordeste. Este baixo consumo deve-se a alguns fatores, como o teor de tanino $(0,27 \%$ a $0,72 \%)$ existente nos tipos cultivados de $A$. occidentale L. Por isso, a Embrapa vem realizando pesquisa objetivando a melhoria dessa característica nos clones anão-precoce CP76 e CP09, via retrocruzamento, com a espécie A. microcarpum L. Neste trabalho, iniciado em 1999, avaliaram-se o tanino, a acidez total (ATT\%), os sólidos solúveis totais (SST), a relação SST/ATT, o pH e a textura de pedúnculos dos genitores empregados nos retrocruzamentos e seus respectivos híbridos, com os seguintes resultados: a) confirmaram-se os baixos teores de tanino $(0,14 \%)$ e de ATT $(0,16 \%)$ no A. microcarpum em relação às médias dos clones CP76 e CP09 $(0,33 \%$ para tanino e $0,26 \%$ para ATT $)$; b) o A. microcarpum também foi superior quanto à relação SST/ATT $(80,6 \%)$ e a textura do pedúnculo $(10,75 \mathrm{~N})$, sendo os valores dos clones de 47,9 e 6,9N, respectivamente; c) estes resultados confirmam a importância do A. microcarpum como pai doador no melhoramento genético; d) os genitores não diferiram quanto aos teores de sólidos solúveis totais (SST) e pH; e) os híbridos entre A. microcarpum e A. occidentale exibiram acentuado vigor híbrido com relação aos teores de tanino, acidez e textura, e ausência de vigor híbrido em relação aos valores do pH e de sólidos solúveis totais (SST); f) não houve efeito nos cruzamentos recíprocos, para a maioria das características estudadas, à exceção do tanino.
\end{abstract}

Termos para indexação: Anacardium microcarpum L.; Anacardium occidentale L.; retrocruzamento; tanino; melhoramento genético; qualidade do pedúnculo.

\section{IMPROVEMENT OF THE DWARF CASHEW TREE: EVALUATION OF THE QUALITY OF THE APPLE AND THE HETEROSIS OF THEIR HYBRIDS}

\begin{abstract}
The in natura consumption of cashew apple is increasing in Brazil after the cultivation of new clones of dwarf cashew developed about two decades ago. In spite of this progress, the consumption is still low since it doesn't reach 1\% of about 1,5 million tons yearly produced in the Northeast region. This low consumption is due to some factors, such as the tannin content $(0,27 \%$ to $0,72 \%$ ) existent in the cashew apple of the cultivated types of $A$. occidentale. The Embrapa is realizing an research aiming to improve the apple characteristics of the dwarf clones CP76 and CP09, by backcrossing with A. microcarpum specie. In this work, initiate in 1999, were evaluated the tannin content, the total acidity (ATT\%), the total soluble solids (SST), the relationship SST/ATT, the pH and the texture of cashew apples of the genitors used in the backcross and their respective hybrids, with the following results: a) the reduced tannin content were confirmed $(0,14 \%)$ and of ATT $(0,16 \%)$ in the A. microcarpum, in relation with the averages of the clones CP76 and CP09 (0,33\% for tannin and 0,26\% for ATT); b) A. microcarpum was also superior concerning the relationship SST/ATT (80,6\%) and the texture of the cashew apple $(10,75 \mathrm{~N})$, with the values for the clones of 47,90 and $6,9 \mathrm{~N}$, respectively; c) these results confirm the importance of A. microcarpum as father donor in the genetic improvement; d) the genitors didn't differ in relation to the contents of total soluble solids (SST) and $\mathrm{pH}$; e) the hybrid among A. microcarpum x A. occidentale exhibited accentuated hybrid vigor in relation to the tannin content, acidity and texture and absence of hybrid vigor, in relation to the values of the $\mathrm{pH}$ and of total soluble solids (SST); f) there wasn't effect in the reciprocal crossings, for most of the studied characteristics, except for the tannin content.
\end{abstract}

Index terms: Anacardium microcarpum L.; Anacardium occidentale L.; backcross, tannin, genetic improvement, quality of the cashew apple .

1 (Trabalho 107/2001). Recebido: 25/05/2001. Aceito para publicação: 09/01/2002. Suporte financeiro: Embrapa Agroindústria Tropical

2 Eng - Agrônomos, Dr. Pesquisadores da Embrapa Agroindústria Tropical, CP 3761, 60.511-110, Fortaleza - CE, crisost@ cnpat.embrapa.br

3 Eng ${ }^{\underline{0}}$ Agrônomo, M. Sc. técnico especializado da Embrapa Agroindústria Tropical

4 Estudantes de Agronomia da UFC; bolsistas do PET e estagiários da Embrapa. 


\section{INTRODUÇÃO}

O consumo de pedúnculo de caju "in natura" vem experimentando incremento no Brasil após o cultivo dos novos clones de cajueiro-anão-precoce, lançados no mercado a partir dos anos oitenta. Eles vêm proporcionando maior produtividade, facilidade na colheita e uniformidade da castanha e do pedúnculo (Barros \& Crisóstomo, 1995). Associados a isso, recentes avanços na área de pós-colheita vêm aperfeiçoando o processo de transporte, embalagem e conservação do pedúnculo, ampliando sua duração para até quinze dias após a colheita, o que está possibilitando a comercialização em mercados distantes do centro de produção ( Filgueiras et al., 1999).

Apesar desses avanços, o consumo ainda é pequeno, cerca de $1 \%$ da produção anual estimada em 1,5 milhão de toneladas/ano (levantamento preliminar não publicado da área de Difusão e Transferência de tecnologia da Embrapa Agroindústria Tropical, 1999). Esse "impedimento" a um maior consumo "in natura" decorre de vários fatores, alguns dos quais intrínsecos ao pseudofruto como a adstringência, devido ao teor de tanino existente no pedúnculo dos clones e de tipos comerciais produzidos por semente, todos da espécie Anacardium occidentale L. Outro problema é a elevada perecibilidade do pedúnculo, que não ultrapassa, após colhido, 48 horas em condições de ambiente.

Os estudos sobre a composição química do pseudofruto do cajueiro têm se restringido a diferentes genótipos da espécie cultivada $A$. occidentale L. e revelado diferentes valores em função do grau de maturidade e procedência da produção. Resultados com amostras de pedúnculos vermelhos e amarelos, procedentes de municípios litorâneos do Ceará, acusaram médias de tanino de $0,40 \%$ e $0,35 \%$, e médias de acidez total de $0,34 \%$ e $0,42 \%$ para pedúnculos vermelhos e amarelos, respectivamente (Moura Fé et al, 1972). Na Índia, Chandran \& Damodaran (1985) analisaram dezesseis tipos de cajueiros e encontraram variação na porcentagem de tanino total de $0,33 \%$ a $0,74 \%$. Filgueiras et al. (1999) apresentaram uma síntese recente sobre a composição química em pedúnculos maduros de cajueiro a qual demonstra a seguinte composição e variação: $\mathrm{pH}$ de 3,5 a 4,5; água de 84,5 a 90,4\%; acidez de 0,22 a 0,52\%; sólidos solúveis totais de 9,8 a 14,0 'Brix; açúcar total de 7,7 a 13,2\%; vitamina C de 139,0 a 187,0 $\mathrm{mg} / 100 \mathrm{~g}$ e tanino de 0,27 a $0,72 \%$. Esses resultados indicam, além de valores elevados para o tanino, a existência de variabilidade genética na espécie $A$. occidentale L., sendo possível a obtenção de progresso por seleção.

Por outro lado, não se conhece a composição química de caracteres de interesse em outras espécies, o que seria importante pela possibilidade de identificar tipos com propriedades desejáveis que poderiam ser empregados em programas de melhoramento genético. Com esse objetivo, foi efetuada uma avaliação do Banco de Germoplasma de caju da Embrapa Agroindústria Tropical onde se destacaram genótipos da espécie A. microcarpum L. por apresentarem, em avaliação preliminar, no campo, algumas características contrastantes e positivas, em relação aos tipos comerciais, sobretudo quanto à adstringência. A partir daí, estes genótipos foram empregados no melhoramento do cajueiro-anão-precoce visando à melhoria do pedúnculo dos clones CP76 e CP09, da espécie $A$. occidentale, pela introdução, via retrocruzamento, de características desejáveis em genótipos da espécie $A$. microcarpum existente no Banco de Germoplasma.

Os objetivos deste trabalho foram: a) caracterização físico-química de pedúnculos dos genitores das duas espécies empregadas no programa de melhoramento; b) caracterização dos cruzamentos (F1's) respectivos, inclusive os recíprocos; e c) estimativas dos valores de heterose nos cruzamentos em relação aos valores de tanino, de acidez total, de textura, de $\mathrm{pH}$ e de sólidos solúveis totais, em amostras de pedúnculos maduros dos genitores e respectivos híbridos.

\section{MATERIAL E MÉTODOS}

O estudo foi realizado em pedúnculos coletados em 1999, em experimentos que estão sendo conduzidos no Campo Experimental da Embrapa Agroindústria Tropical, em PacajusCE. O experimento faz parte do programa de melhoramento genético, objetivando a melhoria do pedúnculo de clones comerciais de cajueiro-anão-precoce pelo método do retrocruzamento, empregando-se genótipos da espécie Anacardium microcarpum L. como pai doador das características baixa adstringência, baixa acidez e textura elevada, e como pai recorrente os clones CP76 e CP09 da espécie Anacardium occidentale L., atualmente, os mais cultivados.

As amostras de pedúnculos maduros foram coletadas no período de setembro-outubro de 1999, em plantas de $A$. microcarpum, nos clones CP76 e CP09 e nos respectivos cruzamentos (F1's), inclusive nos recíprocos. Foram coletados oito pedúnculos numa única planta no $A$. microcarpum e dez em quatro plantas de cada um dos outros seis genótipos, os quais, após identificados, foram analisados no laboratório de póscolheita da Embrapa Agroindústria Tropical para as seguintes características: Textura (firmeza de polpa), realizada nos pedúnculos íntegros com penetrômetro manual FT011 com ponteiras de $8 \mathrm{~mm}$ de diâmetro. (A punção foi feita na porção basal do pedúnculo tendo sido efetuadas três leituras por pedúnculo e os resultados expressos em Newton $(\mathrm{N})$, como citado por Moura, 1998); Sólidos Solúveis Totais (SST), efetuado com refratômetro de acordo com metodologia recomendada pela AOAC (1992) e expressa em graus Brix; Acidez Total Titulável (ATT), efetuada no suco conforme técnica recomendada por Kramer (1973), citada por Menezes (1992); relação SST/ATT, obtida através do quociente entre as análises; $\mathrm{pH}$, obtido diretamente no suco, seguindo a técnica recomendada por AOAC (1992), conforme Menezes (1992); Tanino a 50\% em água, determinado conforme metodologia de Reicher et al. (1981), citada por Moura (1998).

Os resultados foram tabulados e as médias dos pais e dos cruzamentos compiladas em tabela e comparadas entre si pela obtenção da estimativa do intervalo de confiança (Little \& Hills, 1978). Foram obtidas, também, as estimativas da heterose de cada cruzamento, conforme Ferh (1987).

\section{RESULTADOS E DISCUSSÃO}

As análises da composição química dos pedúnculos (Tabela 1 ) revelaram valores baixos para tanino $(0,14 \%)$ e para 
acidez total $(0,16 \%)$ no pai doador (A. microcarpum ), quando comparado com os valores encontrados nos genótipos de $A$. occidentale, clones CP76 (0,34\% para tanino e 0,25\% para acidez total) e CP09 (0,32\% para tanino e 0,26\% para acidez total). Com relação à textura do pedúnculo, o genótipo doador também foi superior, com a média de 10,75 N contra 5,86 N e 7,86 N nos clones $\mathrm{CP} 76$ e CP09, respectivamente. A estimativa do intervalo de confiança acusou diferença entre a média de Tanino no $A$. microcarpum e aquelas dos demais genótipos (Tabela 1). Quanto aos resultados da Acidez Total, da relação SST/ATT e da Textura , verificou-se que, apesar da acentuada diferença entre as médias em relação ao A. microcarpum, a variabilidade dos dados não possibilitou a discriminação do ponto de vista estatístico ao nível de $5 \%$ de probabilidade. Isso provavelmente ocorrerá com o aumento da amostra.

Apesar de a literatura não registrar uma classificação quanto aos níveis adequados ao mercado para esses caracteres, alguns autores destacam que valores de tanino, a partir de $0,55 \%$, torna inadequada a qualidade do pedúnculo para o consumo e consideram razoáveis valores abaixo de $0,35 \%$ (Chandran \& Damodaram, 1985). A este respeito, testes sensoriais realizados em pedúnculos com estes teores têm indicado rejeição de parte dos provadores, evidenciando que, apesar de "aceitáveis", estes níveis $(0,32$ a $0,35 \%)$ não são ainda os ideais para uma maior inserção no mercado, sobretudo para pessoas de regiões não tropicais. É importante destacar que os clones cultivados e empregados neste estudo apresentaram teor médio de tanino de $0,33 \%$ (Tabela 1), contrastando com os baixos valores encontrados no A. microcarpum $(0.14 \%)$. Isto torna evidente a possibilidade de melhoria do pedúnculo daqueles clones via retrocruzamento.

É importante destacar, também, os maiores valores do A. microcarpum em relação aos clones, quanto à relação SST/ ATT, uma vez que essa relação indica o grau de doçura de um determinado fruto. Os valores encontrados neste trabalho foram de 80,6 e 47,3 para A. microcarpum e a média dos dois clones, respectivamente. Deve-se destacar que a literatura não registra dados com aquela magnitude $(80,6)$. Menezes (1992) encontrou valores de 36,03 e 41,03 para pedúnculos com zero a 48 horas de armazenamento, respectivamente. Moura (1998) avaliou nove clones de cajueiro-anão-precoce e encontrou uma variação de 29,93 até 46,48. Alves et al. (1997), citado por Moura (1998), observou que pedúnculos do clone CP76 atingiram até 59,5 para essa relação, quando completamente maduros. Esses resultados confirmam mais uma vez a importância do A. microcarpum como doador no programa de melhoramento genético do cajueiro-anãoprecoce visando à qualidade do pedúnculo. A partir deles, podemse prever resultados satisfatórios com os retrocruzamentos que estão sendo praticados visando principalmente à redução de tanino dos clones cultivados. Abre também uma perspectiva quanto à investigação nas demais espécies de Anacardium visando ao aproveitamento nessas pesquisas.

Na Tabela 2, temos as estimativas de heterose para os cruzamentos realizados. Constataram-se maiores médias dos híbridos em relação à média dos pais para tanino, acidez e textura em todos os cruzamentos, ocasionando heterose positiva para esses caracteres. Os maiores valores de heterose foram para tanino e acidez total. As estimativas para tanino variaram de $29,2 \%$ a $100 \%$ e as de acidez variaram de $2,44 \%$ a $52,38 \%$, evidenciando elevado vigor híbrido nos cruzamentos, o que é indicativo de divergência gênica nos locos que condicionam esses caracteres, nas duas espécies. Também para textura, verificou-se vigor híbrido embora inferior aos valores encontrados para os outros caracteres já comentados. $\mathrm{O}$ pH apresentou a menor heterose, sendo, conseqüentemente, o caráter de menor divergência gênica, tendo apresentado valores de heterose negativa em três cruzamentos.

Observando-se os dados dos clones na Tabela 2, podese efetuar uma comparação entre os dois, uma vez que se constataram maiores estimativas de heterose (para tanino e acidez) nos cruzamentos com o CP09, evidenciando ser este mais divergente do A. microcarpum que o CP76. Ainda nesta tabela, analisando-se as médias dos híbridos recíprocos e as estimativas de heterose, pode-se afirmar que não houve efeito de cruzamentos recíprocos para a maioria dos caracteres estudados, à exceção do tanino, que apresentou efeito divergente no F1 quando se inverteu a direção do cruzamento. A este respeito, pode-se verificar que, no cruzamento A.m. x CP09, a média do híbrido foi de $0,46 \%$, e a heterose foi de $100,0 \%$. No mesmo

TABELA 1 - Médias e intervalo de confiança (IC) para valores de Tanino, de Acidez Total, de Sólidos Solúveis Totais, SST/ATT, de pH e de Textura, referentes ao Anacardium microcarpum L. dos clones CP76 e CP09 de Anacardium occidentale L. e seus respectivos F1s inclusive os recíprocos. Fortaleza-CE, 2000.

\begin{tabular}{|c|c|c|c|c|c|c|c|c|c|c|c|c|}
\hline \multirow{3}{*}{ Genótipo } & \multicolumn{12}{|c|}{ Variáveis $^{1}$} \\
\hline & \multicolumn{2}{|c|}{ Tanino $(\%)$} & \multicolumn{2}{|c|}{ Acidez total $(\%)$} & \multicolumn{2}{|c|}{ Sólidos solúveis (\%) } & \multicolumn{2}{|c|}{ SST/ATT } & \multirow[b]{2}{*}{ Média } & \multirow{2}{*}{$\begin{array}{ll}\mathrm{pH} & \\
& \mathrm{IC}\end{array}$} & \multicolumn{2}{|c|}{ Textura $(\mathrm{N})$} \\
\hline & Média & IC & Média & IC & Média & IC & Média & IC & & & Média & IC \\
\hline \multicolumn{13}{|l|}{ Genitores } \\
\hline A. microcarpum & 0,14 & $(0,08-0,19)$ & 0,16 & $(0,08-0,23)$ & 12,6 & $(11,1-14,1)$ & 83,0 & $(37,3-128,5)$ & 5,1 & $(4,9-5,3)$ & 10,8 & $(1,6-25,5)$ \\
\hline \multicolumn{13}{|l|}{ A. occidentale } \\
\hline Clone CP76 & 0,34 & $(0,31-0,37)$ & 0,25 & $(0,22-0,3)$ & 12,1 & $(11,4-12,8)$ & 47,1 & $(40,0-54,3)$ & 4,8 & $(4,5-5,0)$ & 5,9 & $(5,9-8,7)$ \\
\hline Clone CP09 & 0,32 & $(0,26-0,38)$ & 0,26 & $(0,12-0,37)$ & 12,0 & $(11,1-12,6)$ & 50,3 & $(20,0-80,7)$ & 4,6 & $(4,1-5,1)$ & 7,9 & $(5,1-9,3)$ \\
\hline \multicolumn{13}{|l|}{ Cruzamentos } \\
\hline A.m. x CP76 & 0,31 & $(0,16-0,45)$ & --- & --- & 12,2 & $(9,8-14,6)$ & --- & --- & 5 & $(4,3-5,0)$ & 10,0 & --- \\
\hline CP76 x A.m. & 0,32 & $(0,26-0,35)$ & 0,21 & $(0,12-0,30)$ & 13,8 & $(12,4-15,2)$ & 70,0 & $(29,8-110,1)$ & 4,6 & $(4,4-5,9)$ & 9,1 & $(1,0-17,2)$ \\
\hline A.m. x CP09 & 0,46 & $(0,34-0,57)$ & 0,32 & $(0,25-0,38)$ & 12,6 & $(10,7-14,5)$ & 39,5 & $(37,0-42,1)$ & 4,7 & $(4,2-5,2)$ & 11,7 & $(7,9-11,9)$ \\
\hline CP09 x A.m. & 0,35 & --- & --- & --- & 11,5 & --- & --- & --- & 4,4 & --- & --- & --- \\
\hline
\end{tabular}

\footnotetext{
'. Médias comparadas entre si e que não têm interseção no intervalo de confiança são diferentes, ao nível de 5\% de probabilidade.
} 
TABELA 2 - Média dos híbridos (MH), média dos pais (MP) e estimativa da heterose (Het) de cruzamentos, inclusive os recíprocos, entre A. microcarpum L. e os clones de cajueiro-anão-precoce CP76 e CP09 (A. occidentale L.) referente aos caracteres tanino, acidez total, sólidos solúveis totais, pH e textura de pedúnculos maduros avaliados em 1999. Fortaleza-CE, 2000.

\begin{tabular}{|c|c|c|c|c|c|c|c|c|c|c|c|c|c|c|c|}
\hline \multirow{2}{*}{ HÍBRIDO } & \multicolumn{3}{|c|}{ Tanino (\%) } & \multicolumn{3}{|c|}{ Acidez Total $(\%)$} & \multicolumn{3}{|c|}{ Sólidos solúveis Totais (\%) } & \multicolumn{3}{|c|}{$\mathrm{pH}$} & \multicolumn{3}{|c|}{ Textura $(\mathrm{N})$} \\
\hline & MH & MP & Het $(\%)$ & MH & MP & Het $(\%)$ & MH & MP & Het $(\%)$ & MH & MP & Het $(\%)$ & MH & MP & Het $(\%)$ \\
\hline A.m. x CP76 & 0,31 & 0,24 & 29,2 & --- & 0,205 & --- & 12,2 & 12,5 & $-2,4$ & 5,0 & 4,95 & 1,01 & 9,99 & 8,31 & 20,22 \\
\hline CP76 x A.m. & 0,32 & 0,24 & 33,3 & 0,21 & 0,205 & 2,44 & 13,8 & 12,5 & 10,4 & 4,6 & 4,95 & $-7,07$ & 9,08 & 8,31 & 9,27 \\
\hline A.m. x CP09 & 0,46 & 0,23 & 100,0 & 0,32 & 0,21 & 52,38 & 12,6 & 12,45 & 1,2 & 4,7 & 4,85 & $-3,09$ & 11,07 & 9,32 & 18,78 \\
\hline CP09 x A.m. & 0,35 & 0,23 & 34,8 & 0,31 & 0,21 & 47,62 & 11,5 & 15,45 & $-7,6$ & 4,4 & 4,85 & $-9,28$ & --- & 9,32 & -- \\
\hline
\end{tabular}

cruzamento, mas na outra ordem, ou seja, CP09 x A.m., a média do híbrido foi de $0,35 \%$ e a heterose foi de $34,8 \%$. Esses resultados indicam que, à exceção desse cruzamento e caráter, qualquer um dos genitores pode ser empregado como macho ou como fêmea quando em programas de cruzamentos artificiais.

\section{CONCLUSÕES}

1. O baixo teor de tanino $(0.14 \%)$ comprovado no A. microcarpum, em relação aos clones de $A$. occidentale $(0,33 \%)$, demonstra sua adequação em programa de melhoramento genético visando à qualidade do pedúnculo:.

2. Os pedúnculos de A. microcarpum e de A. occidentale mostraram-se semelhantes quanto aos teores de sólidos solúveis totais e de $\mathrm{pH}$.

3. Os híbridos entre A. microcarpum e A. occidentale exibiram acentuado vigor híbrido com relação aos teores de tanino, acidez e textura e ausência de vigor híbrido em relação aos valores do $\mathrm{pH}$ e de sólidos solúveis totais.

4. Com exceção do tanino, não se verificou efeito dos cruzamentos recíprocos entre $A$. microcarpum e os clones anão-precoce de A. occidentale para acidez total, sólidos solúveis totais, $\mathrm{pH}$ e textura dos pedúnculos.

\section{REFERÊNCIAS BIBLIOGRÁFICAS}

INSTITUTO ADOLFO LUTZ. Normas analíticas, métodos químicos e físicos para análise de alimentos. 3. ed. São Paulo, 1985. v. 1.533p.

ASSOCIATION OF OFFICIAL ANALYTICAL CHEMISTRY. Official methods of Analysis of the Association of Official Analytical Chemistry. 11.ed. Washington, 1992. 1115p.

BARROS, L. de M.; CRISÓSTOMO, J.R. Melhoramento genético do cajueiro. In: ARAÚJO, J. P. P. de, SILVA, V. V. da (Org.)
Cajucultura: modernas técnicas de produção. Fortaleza: EMBRAPA - CNPAT, 1995.p. 73-93.

CHANDRAN, V. T.; DAMODARAN, V. K. Physico - chemical qualities of cashew apples of Righ yielding types. Acta Horticulturae, Wageningen, n.108, p. 165-172, 1985.

FEHR, W.R. Heterosis. Principles of cultivar Development. New York: Macmillan Publishing Company, 1987. p.115-119.

FILGUEIRAS, H. A. C; ALVES, R.E.; MOSCA, J.L.; MENEZES, J. B. Cashew apple for fresh consumption: research on harvest and post-harvest technology in Brasil. Acta Horticulturae, Wageningen, n.485, p. 155-160, 1999.

LITTLE; T. M.; HULLS, F. J.. Agricultural experimentation design and analysis. New York: Ed. John Wiley and Sons, 1978. $350 \mathrm{p}$.

MENEZES, J.B. Armazenamento refrigerado de pedúnculos do caju (Anacardium occidentale, L.) sob atmosfera ambiente e modificada. 1992. 102f. Dissertação (mestrado) - Escola Superior de Agricultura de Lavras, Lavras, 1992.

MOURA, C. F. M. Qualidade de pedúnculos de clones de cajueiro-anão-precoce (Anacardium occidentale, L. var. nanum) irrigados. 1998. 96f. Dissertação (mestrado) - Universidade Federal do Ceará, Fortaleza, 1998.

MOURA FÉ, J. de A; HOLANDA, L.F.F. de; MARTINS C.B.; MAIA, G.A. Características químicas do hipocarpo do caju (Anacardium occidentale, L.) . Ciência Agronômica, v.2 , n. 2, p.103-108, 1972.

REICHER, F.; SIERAKOWSKI, M.R.; CORREA, J. B. C. Determinação espectroftométrico de taninos pelo reativo fosfotúngstico-fosfomolíbdico. Arquivos de Biologia e tecnologia, Curitiba, v. 24, n.4, p. 407 - 411, 1981. 